\title{
Thermophysical Properties of Mixtures of Titanium(IV) Isopropoxide (TTIP) and $p$-Xylene
}

\author{
Alexander Keller ${ }^{\mathrm{a}}$, Irenäus Wlokas ${ }^{\mathrm{b}}$, Maximilian Kohns ${ }^{\mathrm{a}, 1}$, Hans Hasse ${ }^{\mathrm{a}}$ \\ ${ }^{a}$ University of Kaiserslautern, Laboratory of Engineering Thermodynamics (LTD), \\ Erwin-Schrödinger-Str. 44, D-67663 Kaiserslautern, Germany \\ ${ }^{b}$ University Duisburg-Essen, Fluid Dynamics, Institute for Combustion and Gas Dynamics, \\ Carl-Benz-Str. 199, D-47057 Duisburg, Germany
}

\section{Abstract}

Titanium(IV) isopropoxide (TTIP) is an important precursor for the production of nanoparticles by spray flame processes. In these processes, the precursor is provided in a solution in a combustible solvent, which is $p$-xylene here. As no thermophysical data for solutions of TTIP in $p$-xylene were available in the literature, they were measured in the present work. The vapor-liquid equilibrium was measured at pressures ranging from 20 to $80 \mathrm{kPa}$. The specific density, viscosity, thermal conductivity, molar isobaric heat capacity, and self-diffusion coefficients were determined experimentally at $101.3 \mathrm{kPa}$ at temperatures between 293.15 and 373.15 K. Sample compositions cover the range from pure TTIP to pure $p$-xylene. Chemical reactions in the studied system were considered. The experiments were carried out in a way that they do not compromise the results for the thermophysical properties. The vapor-liquid equilibrium data were correlated using the NRTL model. Empirical correlations were established for the other properties. The results provide a rational basis for spray flame process design.

Keywords: spray flame synthesis, thermal conductivity, vapor-liquid equilibrium, NRTL, diffusion coefficients

\footnotetext{
${ }^{1}$ Corresponding author; maximilian.kohns@mv.uni-kl.de
} 


\section{Introduction}

Titanium(IV) isopropoxide $\left(\mathrm{Ti}\left(\mathrm{O}\left(\mathrm{CH}_{3}\right)_{2} \mathrm{CH}\right)_{4}\right.$, TTIP) is an interesting precursor for the production of $\mathrm{TiO}_{2}$ nanoparticles in the spray flame process [1-3]. In the spray flame process, the precursors are dissolved in a combustible solvent and then sprayed into the hot atmosphere of a pilot flame, in which they evaporate and burn. The reactions in the flame lead to the formation of metal oxide nanoparticles. In contrast to the pure gas-phase process route, the choice of the nanoparticle precursor is not limited by its vapor pressure. Instead, the spray droplet formation and characteristics, their secondary breakup and evaporation and the transport processes within the droplet during combustion impact the product properties. In consequence, the quality and the properties of the produced nanoparticles depend strongly on the thermophysical properties of the precursor solutions [1]. Accordingly, thermophysical data on the precursor solutions are needed for the spray flame process design, namely as a basis for process modeling and simulations [1,4-8]. In particular, information on the vapor-liquid equilibrium (VLE), density, viscosity, thermal conductivity, isobaric heat capacity, and diffusion coefficients of the studied precursor + solvent mixtures has to be available. Despite the high interest in spray flame nanoparticle synthesis from TTIP solutions, thermophysical data are only available for pure TTIP and pure combustible solvents, but not for their mixtures. Recent attempts to introduce a standardized synthesis setup within the SpraySyn initiative [9] provide further motivation to investigate the thermophysical properties of precursor solutions.

TTIP is a metal alkoxide which is a liquid at ambient conditions. Bradley et al. [10] give an overview of metal alkoxides. Besides synthesis routes and chemical 
properties, they provide information on thermophysical properties of the pure metal alkoxides, such as density and viscosity at ambient conditions. Thomas and Davies [11] measured liquid TTIP densities from 298 to $396 \mathrm{~K}$ and viscosities from 403 to 463 K. Nikitin et al. [12] determined the critical temperature and pressure of TTIP using a pulse-heating method. Bradley et al. [13] measured the boiling temperature of TTIP at low pressures (0.013 and $0.66 \mathrm{kPa})$. Lappert et al. [14] and Bradley and Hillyer [15] measured the heat of formation and the heat of combustion of TTIP.

It is well-known that at elevated temperatures, metal alkoxides can decompose chemically by splitting off the corresponding alcohol, which is 2-propanol in case of TTIP. Siefering and Griffin [16] investigated the decomposition of TTIP vapor by measuring the $\mathrm{TiO}_{2}$-growth rate for different temperatures and pressures. Bradley and coworkers $[17,18]$ showed that for zirconium alkoxides, the hydrolysis to zirconium oxide and the corresponding alcohol is a chain reaction, which is catalyzed by glass surfaces. Ritala et al. [19] assumed a similar mechanism also for titanium alkoxides such as TTIP, which are chemically similar to zirconium alkoxides.

The most popular solvent for TTIP in the flame spray pyrolysis process is 2propanol. However, the quite high vapor pressure of 2-propanol limits the range of the synthesis parameters towards the low pressure. In lab-scale investigations, the process pressure is a comfortable parameter to control the residence time and the flame properties. Thus, in this work, $p$-xylene was investigated as an alternative solvent with low vapor pressure.

To summarize: the decomposition mechanisms and some pure component properties of TTIP are known from literature studies. However, no data on thermophysical properties of solutions of TTIP are available, which hampers spray 
flame process design and simulation. Hence, in the present work, a comprehensive experimental study on the VLE, specific density, viscosity, thermal conductivity, molar isobaric heat capacity, and self-diffusion coefficients of mixtures of TTIP and $p$-xylene was carried out. Correlations of the new experimental data are provided to facilitate the use of the results, e.g. in numerical simulations. In the present work, the reported uncertainties are standard uncertainties, which include statistical and method uncertainties. For the sake of brevity, we write "density" for "specific density" and “isobaric heat capacity” for "molar isobaric heat capacity”.

\section{Experimental}

\subsection{Chemicals and sample preparation}

TTIP and p-xylene were purchased from Sigma-Aldrich and analyzed by quantitative Proton Nuclear Magnetic Resonance $\left({ }^{1} \mathrm{H}-\mathrm{NMR}\right)$ spectroscopy in our laboratory. Results are presented in Table 1. Both chemicals were used without further purification. Due to the reaction of TTIP with air moisture, TTIP was handled in a dry nitrogen atmosphere in a glove-box. Samples were hermetically sealed in $40 \mathrm{~mL}$ glass vials. A laboratory balance (Mettler-Toledo AG204) with an accuracy of $\pm 0.0001 \mathrm{~g}$ according to the calibration protocol was used for the gravimetrical sample preparation. The balance accuracy results in an uncertainty in the mole fraction of both components of $\pm 0.0005 \mathrm{~mol} \mathrm{~mol}^{-1}$.

\subsection{Measurements}

\subsubsection{Vapor-liquid equilibrium}

The VLE measurements were performed using a recirculating glass still similar to the one described by Rafflenbeul and Hartmann [20]. A detailed description of the setup and its operation is given by Hasse [21]. The pressure is measured with a 
pressure sensor (WIKA P-30) with an uncertainty of $\pm 0.4 \mathrm{kPa}$. The temperature is measured in the phase separation chamber with a Pt100 resistance thermometer that was calibrated in our laboratory against a standard certified by PhysikalischTechnische Bundesanstalt (PTB) Braunschweig. The uncertainty of the temperature measurement is $\pm 0.2 \mathrm{~K}$. To test the apparatus, the boiling temperature of $p$-xylene was measured at pressures ranging from 20 to $80 \mathrm{kPa}$. The deviation between our data to the mean of the literature data in the observed boiling temperature is less than $\pm 0.2 \mathrm{~K}$ for all pressures, which is below the uncertainty specified above.

The mole fractions of TTIP and p-xylene in the coexisting phases were analyzed using quantitative ${ }^{1} \mathrm{H}-\mathrm{NMR}$ spectroscopy. Analysis by gas chromatography was tested but not found feasible due to TTIP decomposition in the device. The ${ }^{1} \mathrm{H}-\mathrm{NMR}$ experiments were carried out with a Bruker Ascend $400 \mathrm{MHz}$ spectrometer, using 8 scans, a pulse width of $10^{\circ}$ and a relaxation delay of $10 \mathrm{~s}$. The accuracy of the NMR analysis was determined by analyzing gravimetrically-prepared mixtures of TTIP and p-xylene. From this analysis, the uncertainty in the mole fraction of both components is estimated to be better than $\pm 0.005 \mathrm{~mol} \mathrm{~mol}^{-1}$.

During some of the VLE measurements, especially at temperatures above $420 \mathrm{~K}$, the formation of small amounts of $\mathrm{TiO}_{2}$ dust was observed visually in the circulating liquid. It results from the thermal decomposition of TTIP at high temperatures, together with a formation of 2-propanol $[10,18,19]$. If in the ${ }^{1} \mathrm{H}-\mathrm{NMR}$ spectra any signal other than those of TTIP and $p$-xylene had an area greater than $1 \%$ of the total area, the measurement was dismissed and is not reported in the present work. Hence, an uncertainty of $\pm 0.01 \mathrm{~mol} \mathrm{~mol}^{-1}$ is obtained for the mole fractions of both 
components in the liquid and gaseous phases. Furthermore, other method uncertainties might arise from this which cannot be quantified precisely.

\subsubsection{Density and viscosity}

Density and viscosity measurements were performed at $101.3 \mathrm{kPa}$ with an instrument of Anton Paar (SVM 3000), which is a combination of a vibrating tube densimeter and a Stabinger viscosimeter. The temperature ranges from 293.15 to 373.15 $\mathrm{K}$ and the sample compositions cover the range from pure TTIP to pure $p$ xylene. The measurements of the density were conducted according to the ASTM method D4052, the uncertainty of the density is estimated to be $\pm 0.0005 \mathrm{~g} \mathrm{~cm}^{-3}$. The measurements of the viscosity were conducted according to the ASTM method D7042, the relative uncertainty is estimated to be $3 \%$. After each set of measurements, the apparatus was cleaned twice with 2-propanol and toluene and flushed with dry air. The temperature was measured with a built-in thermometer for which the manufacturer reports an uncertainty of $\pm 0.05 \mathrm{~K}$. The apparatus was calibrated with calibration standards provided by the manufacturer. For validation, the density and viscosity of pure $p$-xylene were measured and compared to literature data. The results are presented in the Supporting Information. Over the entire temperature range, the maximum deviation of our density data to the mean of the literature data is below $0.0004 \mathrm{~g} \mathrm{~cm}^{-1}$, and the maximum relative deviation of our viscosity data to the mean of the literature data is below $3 \%$, which is within the uncertainties specified above for both properties.

\subsubsection{Thermal conductivity and isobaric heat capacity}

Thermal conductivity and isobaric heat capacity measurements were performed at $101.3 \mathrm{kPa}$ with an instrument of flucon fluid control GmbH (LAMBDA), in which 
the sensor and sample are thermostatted by a double jacket vessel. The temperatures were 293.15, 313.15 and $333.15 \mathrm{~K}$ and the sample compositions cover the range from pure TTIP to pure $p$-xylene. In the instrument, the thermal conductivity $\lambda$ and the thermal diffusivity $a$ are measured with the transient hot wire liquid thermal conductivity method according to ASTM method D7896. The isobaric heat capacity $C_{\mathrm{p}}$ is determined by the relationship

$$
c_{\mathrm{p}}=\frac{\lambda \cdot \bar{M}}{a \cdot \rho},
$$

where $\rho$ is the density of the liquid, which was determined as explained above, and $\bar{M}$ is the mean molar mass of the mixture. For each data point, the values for $\lambda$ and $c_{\mathrm{p}}$ were averaged over at least $5 \mathrm{~min}$. The uncertainty of the thermal conductivity measurement is estimated to be below $\pm 5.2 \mathrm{~mW} \mathrm{~m}^{-1} \mathrm{~K}^{-1}$, and the relative uncertainty of the isobaric heat capacity measurement is estimated to be below $5 \%$. After each set of measurements, the apparatus was cleaned with 2-propanol and toluene and flushed with dry air. The temperature was measured with a built-in Pt100 resistance thermometer which was tested in our laboratory against a standard certified by PTB Braunschweig. The uncertainty of the temperature measurement is $\pm 0.2 \mathrm{~K}$. The apparatus was calibrated to the thermal conductivity of toluene at $293.15 \mathrm{~K}$. For validation, the thermal conductivity and isobaric heat capacity of pure $p$-xylene were measured and compared to literature data. The results are presented in the Supporting Information. Over the entire temperature range, the maximum deviation of our thermal conductivity data to the mean of the literature data is below $\pm 4 \mathrm{~mW} \mathrm{~m}^{-1} \mathrm{~K}^{-1}$, and the maximum relative deviation of our isobaric heat capacity data to the mean of 
the literature data is below $2 \%$, which is within the uncertainties specified above for both properties.

\subsubsection{Self-Diffusion}

${ }^{1} \mathrm{H}-\mathrm{NMR}$ measurements of self-diffusion coefficients of TTIP and $p$-xylene were conducted at $101.3 \mathrm{kPa}$ using a Bruker Ascend $400 \mathrm{MHz}$ spectrometer as explained in more detail in the Supporting Information. The temperatures were 288.15, 298.15 and 308.15 $\mathrm{K}$ and the sample compositions cover the range from pure TTIP to pure $p$ xylene. In the spectrometer, the stimulated spin-echo technique with bipolar pulsed gradients as described by Stejskal and Tanner [22] is applied. The relative uncertainty of the self-diffusion coefficients is estimated to be $2 \%$. The spectrometer's temperature sensor was calibrated in our laboratory against a standard certified by PTB Braunschweig. The uncertainty of the temperature measurement is estimated to be below $\pm 0.2 \mathrm{~K}$.

\section{Modeling}

\subsection{Vapor-liquid equilibrium}

The VLE is modeled with the extended Raoult's law,

$$
p_{i}^{\mathrm{S}} \cdot x_{i} \cdot \gamma_{i}=p \cdot y_{i}
$$

where $x_{i}$ and $y_{i}$ are the mole fractions of component $i$ in the liquid and gas phase,

$p_{i}^{\mathrm{S}}$ is the vapor pressure of component $i, \gamma_{\mathrm{i}}$ is the liquid phase activity coefficient of component $i$ and $p$ is the pressure in the system. The pressure dependence of the chemical potential in the liquid phase is neglected and the vapor phase is treated as an ideal gas mixture. The vapor pressures $p_{i}^{S}$ of the pure substances TTIP (1) and $p$ xylene (2) are modeled with a three parameter Antoine type equation 


$$
\ln \left(p_{i}^{\mathrm{S}} / \mathrm{kPa}\right)=A_{i}-\frac{B_{i}}{T / \mathrm{K}+C_{i}},
$$

where $T$ is the temperature in $\mathrm{K}$ and $A_{i}, B_{i}$ and $C_{i}$ are adjustable parameters. The non-ideality of component $i$ in the liquid phase is described with activity coefficients $\gamma_{\mathrm{i}}$ modeled by the NRTL equation,

$$
\ln \gamma_{i}=x_{j}^{2} \cdot\left[\tau_{j i} \cdot\left(\frac{G_{j i}}{x_{i}+x_{j} \cdot G_{j i}}\right)^{2}+\frac{\tau_{i j} G_{i j}}{\left(x_{j}+x_{i} \cdot G_{i j}\right)^{2}}\right]
$$

where

$$
\ln G_{i j}=-\alpha_{i j} \cdot \tau_{i j} \text {. }
$$

The $\tau_{\mathrm{ij}}$ 's and $\alpha_{i j}=\alpha_{j i}$ are adjustable parameters which were obtained from a fit to the measured VLE data.

\subsection{Density, thermal conductivity and isobaric heat capacity}

The density $\rho$ is related to the molar volume $v$ of a mixture by

$$
v=\frac{\bar{M}}{\rho},
$$

where $\bar{M}$ is the mean molar mass of the mixture. The molar volume of a mixture can be written as

$$
v=x_{1} v_{1}^{\text {pure }}+x_{2} v_{2}^{\text {pure }}+v^{\mathrm{E}}
$$

where the $v_{i}^{\text {pure }}$ are the pure component molar volumes and $v^{\mathrm{E}}$ is the molar excess volume. The temperature dependence of the pure component molar volumes is correlated by

$$
v_{i}^{\text {pure }} / \mathrm{m}^{3} \mathrm{~mol}^{-1}=a_{i}+b_{i} \cdot(T / \mathrm{K})+c_{i} \cdot(T / \mathrm{K})^{2},
$$


where, $a_{i}, b_{i}$ and $c_{i}$ are adjustable parameters. The molar excess volume is described using a Redlich-Kister correlation,

$$
v^{\mathrm{E}} / \mathrm{m}^{3} \mathrm{~mol}^{-1}=(E+F \cdot(T / \mathrm{K})) \cdot x_{1} x_{2},
$$

where $E$ and $F$ are adjustable parameters. Thermal conductivities $\lambda$ (in units of $\mathrm{mW} \mathrm{m} \mathrm{m}^{-1}$ ) and molar isobaric heat capacities $c_{\mathrm{p}}$ (in units of $\mathrm{J} \mathrm{mol}^{-1} \mathrm{~K}^{-1}$ ) are correlated in the same way as the molar volume (in units of $\mathrm{m}^{3} \mathrm{~mol}^{-1}$ ) by means of Eq. (7) - (9).

\subsection{Viscosity}

Mixture viscosities $\eta$ are described with the Jouyban-Acree correlation [23]

$$
\begin{aligned}
\ln \frac{\eta}{\mathrm{mPa} \mathrm{s}} & =x_{1} \ln \left(\frac{\eta_{1}^{\text {pure }}}{\mathrm{mPa} \mathrm{s}}\right)+x_{2} \ln \left(\frac{\eta_{2}^{\text {pure }}}{\mathrm{mPa} \mathrm{s}}\right)+E\left(\frac{x_{1} x_{2}}{T / \mathrm{K}}\right) \\
& +F\left(\frac{x_{1} x_{2}\left(x_{1}-x_{2}\right)}{T / \mathrm{K}}\right)+G\left(\frac{x_{1} x_{2}\left(x_{1}-x_{2}\right)^{2}}{T / \mathrm{K}}\right)
\end{aligned}
$$

where $E, F$ and $G$ are adjustable parameters. The temperature-dependent pure component viscosities $\eta_{i}^{\text {pure }}$ are correlated by

$$
\eta_{i}^{\text {pure }}=a_{i} \cdot \exp \left(\frac{b_{i}}{T / \mathrm{K}}\right)+c_{i}
$$

where $a_{i}, b_{i}$ and $c_{i}$ are adjustable parameters.

\subsection{Self-Diffusion}

Self-diffusion coefficients $D_{i}$ of both components in mixtures of TTIP and $p$ xylene are correlated separately for TTIP and $p$-xylene as

$$
\begin{aligned}
D_{i} /\left(10^{-9} \mathrm{~m}^{2} \mathrm{~s}^{-1}\right) & =a_{i}+b_{i} \cdot(T / \mathrm{K})+\left(c_{i}+d_{i} \cdot(T / \mathrm{K})\right) \cdot x_{i}, \\
& +\left(e_{i}+f_{i} \cdot(T / \mathrm{K})\right) \cdot x_{i}^{2}
\end{aligned}
$$

where $a_{i}-f_{i}$ are adjustable parameters.

\subsection{Fitting procedure}


The adjustable parameters in the correlations introduced above were obtained by a least squares minimization using the MATLAB solver "Isqnonlin". For the VLE, for all measured $x_{j}^{\text {exp }}$ the objective function

$$
\mathrm{OF}_{\mathrm{VLE}}=\sum_{j=1}^{N_{\mathrm{p}}}\left(\frac{T_{j}^{\exp }-T_{j}^{\mathrm{cal}}}{T_{j}^{\exp }}\right)^{2}+\sum_{j=1}^{N_{\mathrm{p}}}\left(\frac{y_{j}^{\exp }-y_{j}^{\mathrm{cal}}}{y_{j}^{\exp }}\right)^{2}
$$

was minimized, where $N_{\mathrm{p}}$ is the number of experimental points. The superscripts “exp” and "cal” denote experimental and calculated results. The objective function for fitting the temperature dependence of the pure component molar volumes and the excess molar volume was

$$
\mathrm{OF}_{v}=\sum_{j=1}^{N \mathrm{p}}\left(\frac{v_{j}^{\exp }-v_{j}^{\mathrm{cal}}}{v_{j}^{\exp }}\right)^{2} .
$$

The viscosity, thermal conductivity, isobaric heat capacity and self-diffusion coefficients were fitted in the same way as the molar volume by means of Eq. (14).

\section{Results and discussion}

In the following section, results for the properties of mixtures of TTIP and $p$ xylene are shown as functions of the composition and the temperature. The experimental results are reported in Tables 2 - 7. The parameters of the correlations (cf. Eq. (2) - (12)) are given in Tables 8 - 12.

\subsection{Vapor-liquid equilibrium}

The experimental data of the VLE in the system TTIP $+p$-xylene are shown together with the NRTL model in Figure 1 for the lowest and highest considered total pressure (20 and $80 \mathrm{kPa})$.

[Figure 1 about here.] 
Figure 1 shows a zeotropic behavior of the system. The model describes the experimental data fairly well. At high temperatures, some deviations are observed that may be related to the beginning decomposition of TTIP.

\subsection{Density}

The experimental data of the density of TTIP and $p$-xylene obtained in the present work are shown in Figure 2 together with the correlations.

[Figure 2 about here.]

The density of mixtures of TTIP and p-xylene increases with increasing amount of TTIP, and, not surprisingly, with decreasing temperature. The correlation describes the experimental data within the experimental uncertainty.

\subsection{Viscosity}

The experimental data of the viscosity of TTIP and p-xylene obtained in the present work are shown in Figure 3 together with the correlations.

[Figure 3 about here.]

The viscosity of mixtures of TTIP and $p$-xylene increases with increasing amount of TTIP, and, not surprisingly, with decreasing temperature. The correlation describes the experimental data well. At high concentrations of TTIP, where a steep increase of the viscosity is observed, some deviations are apparent, especially at low temperatures. These deviations were, however, not deemed to be so important as to resort to a more complex correlation, which would involve the risk of overfitting.

\subsection{Thermal conductivity}

The experimental data of the thermal conductivity of TTIP and p-xylene obtained in the present work are shown in Figure 4 together with the correlations.

[Figure 4 about here.] 
The thermal conductivities of pure TTIP and pure $p$-xylene have similar values in the studied temperature range. In mixtures of TTIP and p-xylene, no significant excess contribution to the thermal conductivity is observed. Therefore, the corresponding Redlich-Kister parameter for the thermal conductivity was set to zero, cf. Table 11. The correlation describes the experimental data within the experimental uncertainty.

\subsection{Isobaric heat capacity}

The experimental data of the isobaric heat capacity of TTIP and p-xylene obtained in the present work are shown in Figure 5 together with the correlations.

[Figure 5 about here.]

For all temperatures, the isobaric heat capacity decreases with increasing amount of TTIP. As expected, the isobaric heat capacity increases with increasing temperature. The correlation describes the experimental data within the experimental uncertainty.

\subsection{Self-Diffusion}

The experimental data of the self-diffusion coefficients of TTIP and $p$-xylene obtained in the present work are shown in Figure 6 together with the correlations.

[Figure 6 about here.]

The self-diffusion coefficients of both TTIP and $p$-xylene decrease with increasing amount of TTIP and decreasing temperature. The self-diffusion coefficient of $p$ xylene is always higher than that of TTIP, which is not astonishing as $p$-xylene is the smaller molecule. Furthermore, the trends in the self-diffusion coefficient data match the expectations: the self-diffusion coefficient of both species is high where the 
viscosity and the density are low and vice versa. The correlation describes the experimental data within the experimental uncertainty.

\section{Conclusions}

In the present work, thermophysical properties of mixtures of Titanium(IV) Isopropoxide (TTIP) and p-xylene, which are of interest for the design of spray flame synthesis process of $\mathrm{TiO}_{2}$ nanoparticles, were studied experimentally. The studied properties are: the vapor-liquid equilibrium, specific densities, viscosities, thermal conductivities, molar isobaric heat capacities, and self-diffusion coefficients. No information on these properties was previously available. Empirical correlations for all properties are provided. They describe the experimental data within their uncertainty. The data and correlations presented here provide a sound basis for the design and optimization of spray flame processes for the production of titanium nanoparticles.

\section{Acknowledgements}

This work was supported by the German Research Foundation (DFG) within the priority program SPP 1980 SPRAYSYN under grant HA 1993/18-1. 


\section{References}

[1] H.K. Kammler, L. Mädler, S.E. Pratsinis, Flame Synthesis of Nanoparticles, Chem. Eng. Technol. 24 (2001) 583-596. doi:10.1002/15214125(200106)24:6<583::AID-CEAT583>3.0.CO;2-H.

[2] R. Mueller, L. Mädler, S.E. Pratsinis, Nanoparticle synthesis at high production rates by flame spray pyrolysis, Chem. Eng. Sci. 58 (2003) 1969-1976. doi: 10.1016/S0009-2509(03)00022-8

[3] W.-N. Wang, I.W. Lenggoro, Y. Terashi, T.O. Kim, K. Okuyama, One-step synthesis of titanium oxide nanoparticles by spray pyrolysis of organic precursors, Mater. Sci. Eng. B. $123 \quad$ (2005) 194-202. doi:10.1016/j.mseb.2005.08.006.

[4] C. Weise, J. Menser, S.A. Kaiser, A. Kempf, I. Wlokas, Numerical investigation of the process steps in a spray flame reactor for nanoparticle synthesis, Proc. Combust. Inst. $35 \quad$ (2015) 2259-2266. doi:10.1016/j.proci.2014.05.037

[5] J. Pyykönen, J. Jokiniemi, Computaional Fluid Dynamic Based Sectional Aerosol Modelling Schemes, J. Aerosol Sci. 31 (2000) 531-550. doi:10.1016/S0021-8502(99)00546-7.

[6] B.H. Chao, R.L. Axelbaum, Triaxial Burke-Schumann Flames with Applications to Flame Synthesis, Combust. Sci. Technol. 156 (2000) 291-314. doi:10.1080/00102200008947307.

[7] W.A. Sirignano, Fluid Dynamics and Transport of Droplets and Sprays, Cambridge University Press, 1999. 
[8] B. Abramzon, W.A. Sirignano, Droplet vaporization model for spray combustion calculations, Int. J. Heat Mass Transf. 32 (1989) 1605-1618. doi:10.1016/0017-9310(89)90043-4.

[9] F. Schneider, S. Suleiman, J. Menser, E. Borukhovich, I. Wlokas, A. Kempf, H. Wiggers, C. Schulz, SpraySyn-A standardized burner configuration for nanoparticle synthesis in spray flames, Rev. Sci. Instrum. 90 (2019) 085108. doi:10.1063/1.5090232

[10] D.C. Bradley, R.C. Mehrotra, D.P. Gaur, Metal alkoxides, Academic Press, London, 1978.

[11] L. H. Thomas, G. H. Davies, Viscosity and molecular association. Part VII. Association of alkyl orthotitanates, J. Chem. Soc. Inorg. Phys. Theor. 0 (1969) 1271-1274. doi:10.1039/J19690001271.

[12] E.D. Nikitin, A.P. Popov, Y.G. Yatluk, V.A. Simakina, Critical properties of some tetraalkoxysilanes and tetraalkoxytitaniums with branched alkyl radicals, Fluid Phase Equilibria. 331 (2012) 1-5. doi:10.1016/j.fluid.2012.06.017.

[13] D.C. Bradley, R.C. Mehrotra, W. Wardlaw, 979. Structural chemistry of the alkoxides. Part III. Secondary alkoxides of silicon, titanium, and zirconium, J. Chem. Soc. Resumed. 0 (1952) 5020-5023. doi:10.1039/JR9520005020.

[14] M. F. Lappert, D. S. Patil, J. Brian Pedley, Standard heats of formation and MC bond energy terms for some homoleptic transition metal alkyls MR n, J. Chem. Soc. Chem. Commun. 0 (1975) 830-831. doi:10.1039/C39750000830.

[15] D. C. Bradley, M. J. Hillyer, Thermochemistry of metal alkoxides. Part 2.Heats of formation of some titanium alkoxides, Trans. Faraday Soc. 62 (1966) 2374-2381. doi:10.1039/TF9666202374. 
[16] K.L. Siefering, G.L. Griffin, Kinetics of Low-Pressure Chemical Vapor Deposition of TiO2 from Titanium Tetraisopropoxide, J. Electrochem. Soc. 137 (1990) 814-818. doi:10.1149/1.2086561.

[17] D.C. Bradley, Metal alkoxides as precursors for electronic and ceramic materials, Chem. Rev. 89 (1989) 1317-1322. doi:10.1021/cr00096a004.

[18] D.C. Bradley, M.M. Faktor, The Pyrolysis of metal alkoxides. Part 2. Kinetic studies in zirconium tetra-tert.-amyloxides, (n.d.). https://pubs.rsc.org/en/content/articlepdf/1959/tf/tf9595502117_ (accessed March 6, 2019).

[19] M. Ritala, M. Leskela, L. Niinisto, P. Haussalo, Titanium isopropoxide as a precursor in atomic layer epitaxy of titanium dioxide thin films, Chem. Mater. 5 (1993) 1174-1181. doi:10.1021/cm00032a023.

[20] L. Rafflenbeul, H. Hartmann, Eine dynamische apparatur zur bestimmung von dampf-flüssigkeits-phasengleichgewichten, Chem.-Tech. 7 (1978) 145-148.

[21] H. Hasse, Dampf-Flüssigkeits-Gleichgewichte, Enthalpien und Reaktionskinetik in formaldehydhaltigen Mischungen., University of Kaiserslautern, 1990.

[22] E.O. Stejskal, J.E. Tanner, Spin Diffusion Measurements: Spin Echoes in the Presence of a Time-Dependent Field Gradient, J. Chem. Phys. 42 (1965) 288292. doi:10.1063/1.1695690.

[23] A. Jouyban, M. Khoubnasabjafari, Z. Vaez-Gharamaleki, Z. Fekari, W.E.Jr. Acree, Calculation of the Viscosity of Binary Liquids at Various Temperatures Using Jouyban-Acree Model, Chem. Pharm. Bull. (Tokyo). 53 (2005) 519_ 523. doi:10.1248/cpb.53.519. 
[24] Anonymous, Messung des Saettigungsdampfdrucks ueber Fluessigkeiten: Isopropyltitanat, Confident. Comp. Res. Rep. (1972), retrieved from the Dortmunder Datenbank.

[25] Dortmunder Datenbank, (2019). www.ddbst.com.

[26] E.M. Fendu, M. Nicolae, F. Oprea, Vapour-liquid equilibrium for tripropylene glycol + aromatic hydrocarbons binary systems: Measurements and modelling, Fluid Phase Equilibria. 425 (2016) 188-195. doi:10.1016/j.fluid.2016.05.032. 
Table 1: Chemical specification.

\begin{tabular}{|c|c|c|}
\hline & CAS reg. no. & analysis method \\
\hline TTIP & $546-68-9$ & Sigma Aldrich $\geq 0,99 \mathrm{~mol} / \mathrm{mol}{ }^{1} \mathrm{H}-\mathrm{NMR}$ spectroscopy \\
\hline p-xylene & $106-42-3$ & Sigma Aldrich $\geq 0,99 \mathrm{~mol} / \mathrm{mol}{ }^{1} \mathrm{H}$-NMR spectroscopy \\
\hline
\end{tabular}

Table 2: Results of the VLE measurements; pressure $p$, temperature $T$, mole fractions in the liquid and vapor phase ( $x_{\text {TTIP }}$ and $\left.y_{\text {TTIP }}\right)$. Uncertainties are $u(p)=0.4 \mathrm{kPa}, u(T)=0.2 \mathrm{~K}$, and $u\left(x_{\mathrm{TTIP}}\right)=u\left(y_{\mathrm{TTIP}}\right)=0.01 \mathrm{~mol} \mathrm{~mol}^{-1}$.

\begin{tabular}{|c|c|c|c|c|c|c|c|}
\hline $\begin{array}{c}p \\
\mathrm{kPa}\end{array}$ & $\begin{array}{l}T \\
\mathrm{~K}\end{array}$ & $\begin{array}{c}x_{\text {TTIP }} \\
\mathrm{mol} \mathrm{mol}^{-1}\end{array}$ & $\begin{array}{c}y_{\mathrm{TTIP}} \\
\mathrm{mol} \mathrm{mol}^{-1}\end{array}$ & $\begin{array}{c}p \\
\mathrm{kPa}\end{array}$ & $\begin{array}{l}T \\
\mathrm{~K}\end{array}$ & $\begin{array}{c}x_{\text {TTIP }} \\
\mathrm{mol} \mathrm{mol}^{-1}\end{array}$ & $\begin{array}{c}y_{\mathrm{TTIP}} \\
\mathrm{mol} \mathrm{mol}^{-1}\end{array}$ \\
\hline \multirow[t]{9}{*}{20} & 364.6 & 0.1412 & 0.0061 & 40 & 384.3 & 0.1437 & 0.0108 \\
\hline & 367.4 & 0.2501 & 0.0199 & & 391.6 & 0.2314 & 0.0231 \\
\hline & 369.4 & 0.2739 & 0.0148 & & 394.7 & 0.2627 & 0.0298 \\
\hline & 377.6 & 0.3581 & 0.0329 & & 396.1 & 0.2948 & 0.0345 \\
\hline & 393.3 & 0.5532 & 0.1025 & & 398.1 & 0.3205 & 0.0398 \\
\hline & 408.7 & 0.7300 & 0.2425 & & 437.5 & 0.6746 & 0.3676 \\
\hline & 401.1 & 0.7153 & 0.1639 & & 455.9 & 0.9180 & 0.7432 \\
\hline & 414.1 & 0.8160 & 0.3123 & 50 & 396.1 & 0.1734 & 0.0151 \\
\hline & 420.8 & 0.8815 & 0.4204 & & 392.0 & 0.1348 & 0.0072 \\
\hline \multirow[t]{8}{*}{30} & 374.3 & 0.1060 & 0.0153 & & 403.7 & 0.3284 & 0.0327 \\
\hline & 377.5 & 0.1335 & 0.0093 & & 407.9 & 0.3532 & 0.0514 \\
\hline & 381.8 & 0.2490 & 0.0181 & 60 & 397.3 & 0.1141 & 0.0113 \\
\hline & 387.8 & 0.2991 & 0.0303 & & 404.9 & 0.1932 & 0.0525 \\
\hline & 409.0 & 0.6719 & 0.1374 & & 410.6 & 0.3349 & 0.0365 \\
\hline & 417.0 & 0.7239 & 0.2194 & & 414.8 & 0.3664 & 0.0570 \\
\hline & 429.8 & 0.8731 & 0.4406 & & 434.4 & 0.6772 & 0.1938 \\
\hline & 434.4 & 0.8946 & 0.5326 & 70 & 410.7 & 0.1875 & 0.0229 \\
\hline \multirow[t]{7}{*}{40} & 380.2 & 0.0168 & 0.0000 & & 416.6 & 0.3456 & 0.0480 \\
\hline & 380.6 & 0.0233 & 0.0017 & & 421.4 & 0.3808 & 0.0674 \\
\hline & 381.0 & 0.0376 & 0.0043 & 80 & 407.8 & 0.1279 & 0.0093 \\
\hline & 381.3 & 0.0509 & 0.0045 & & 413.1 & 0.1824 & 0.0182 \\
\hline & 381.6 & 0.0630 & 0.0061 & & 424.0 & 0.3561 & 0.0575 \\
\hline & 382.5 & 0.0907 & 0.0063 & & 421.6 & 0.3356 & 0.0468 \\
\hline & 383.4 & 0.1112 & 0.0085 & & 440.8 & 0.5347 & 0.1695 \\
\hline
\end{tabular}


Table 3: Results of the density measurements; density $\rho$, liquid mole fraction $x_{\text {TTIP }}$ and temperature $T$. The uncertainties are $u(\rho)=0.0005 \mathrm{~g} \mathrm{~cm}^{-3}$, $u\left(x_{\text {TTIP }}\right)=0.0005 \mathrm{~mol} \mathrm{~mol}^{-1}$ and $u(T)=0.05 \mathrm{~K}$.

\begin{tabular}{c|ccccccccc}
\hline \hline $\begin{array}{c}x_{\text {TIIP }} \\
\mathrm{mol} \mathrm{mol}^{-1}\end{array}$ & $T=293.15 \mathrm{~K}$ & $303.15 \mathrm{~K}$ & $313.15 \mathrm{~K}$ & $323.15 \mathrm{~K}$ & $333.15 \mathrm{~K}$ & $343.15 \mathrm{~K}$ & $353.15 \mathrm{~K}$ & $363.15 \mathrm{~K}$ & $373.15 \mathrm{~K}$ \\
\hline 0.0000 & 0.8609 & 0.8522 & 0.8434 & 0.8347 & 0.8259 & 0.8169 & 0.8080 & 0.7990 & 0.7896 \\
0.0401 & 0.8695 & 0.8605 & 0.8515 & 0.8424 & 0.8334 & 0.8243 & 0.8152 & 0.8060 & 0.7967 \\
0.0871 & 0.8781 & 0.8687 & 0.8594 & 0.8502 & 0.8410 & 0.8318 & 0.8225 & 0.8131 & 0.8037 \\
0.1382 & 0.8877 & 0.8778 & 0.8680 & 0.8582 & 0.8487 & 0.8393 & 0.8298 & 0.8203 & 0.8109 \\
0.1994 & 0.8979 & 0.8874 & 0.8770 & 0.8667 & 0.8567 & 0.8469 & 0.8372 & 0.8276 & 0.8179 \\
0.2719 & 0.9062 & 0.8947 & 0.8840 & 0.8737 & 0.8635 & 0.8536 & 0.8439 & 0.8342 & 0.8244 \\
0.3593 & 0.9170 & 0.9044 & 0.8929 & 0.8820 & 0.8714 & 0.8612 & 0.8513 & 0.8414 & 0.8315 \\
0.4654 & 0.9289 & 0.9152 & 0.9027 & 0.8911 & 0.8800 & 0.8693 & 0.8590 & 0.8489 & 0.8390 \\
0.5987 & 0.9413 & 0.9261 & 0.9125 & 0.9001 & 0.8885 & 0.8774 & 0.8667 & 0.8564 & 0.8462 \\
0.7700 & 0.9531 & 0.9362 & 0.9214 & 0.9081 & 0.8959 & 0.8845 & 0.8736 & 0.8631 & 0.8529 \\
1.0000 & 0.9660 & 0.9473 & 0.9298 & 0.9154 & 0.9027 & 0.8912 & 0.8802 & 0.8696 & 0.8593 \\
\hline \hline
\end{tabular}

Table 4: Results of the viscosity measurements; viscosity $\eta$, liquid mole fraction $x_{\text {TTIP }}$ and temperature $T$. The uncertainties are $u_{\mathrm{r}}(\eta)=3 \%$, $u\left(x_{\text {TTIP }}\right)=0.0005 \mathrm{~mol} \mathrm{~mol}^{-1}$ and $u(T)=0.05 \mathrm{~K}$.

\begin{tabular}{c|cccccccccc}
\hline \hline $\begin{array}{c}x_{\text {TTIP }} \\
\mathrm{mol} \mathrm{mol}^{-1}\end{array}$ & $T=293.15 \mathrm{~K}$ & $303.15 \mathrm{~K}$ & $313.15 \mathrm{~K}$ & $323.15 \mathrm{~K}$ & $333.15 \mathrm{~K}$ & $343.15 \mathrm{~K}$ & $353.15 \mathrm{~K}$ & $363.15 \mathrm{~K}$ & $373.15 \mathrm{~K}$ \\
\hline 0.0000 & 0.65894 & 0.57716 & 0.51173 & 0.45713 & 0.41281 & 0.37636 & 0.34670 & 0.32305 & 0.29867 \\
0.0401 & 0.67099 & 0.58811 & 0.52264 & 0.46554 & 0.42071 & 0.38363 & 0.35188 & 0.32547 & 0.30300 \\
0.0871 & 0.70979 & 0.62152 & 0.54936 & 0.48958 & 0.44153 & 0.40106 & 0.36193 & 0.33864 & 0.31670 \\
0.1382 & 0.76517 & 0.66486 & 0.58127 & 0.51618 & 0.46447 & 0.42257 & 0.38709 & 0.35691 & 0.33100 \\
0.1994 & 0.83728 & 0.71527 & 0.62377 & 0.55006 & 0.49267 & 0.44629 & 0.40839 & 0.37220 & 0.34761 \\
0.2719 & 0.91425 & 0.76951 & 0.66414 & 0.58489 & 0.52080 & 0.47181 & 0.43110 & 0.39548 & 0.36616 \\
0.3593 & 1.04190 & 0.85502 & 0.72576 & 0.63262 & 0.55971 & 0.50446 & 0.45762 & 0.41884 & 0.38618 \\
0.4654 & 1.23460 & 0.97237 & 0.80578 & 0.69216 & 0.60745 & 0.54333 & 0.49133 & 0.44818 & 0.41225 \\
0.5987 & 1.53010 & 1.13740 & 0.91112 & 0.76640 & 0.66452 & 0.58825 & 0.52869 & 0.48225 & 0.44197 \\
0.7700 & 2.05280 & 1.39800 & 1.06340 & 0.87098 & 0.74421 & 0.65185 & 0.58164 & 0.52521 & 0.47976 \\
1.0000 & 3.14432 & 1.84518 & 1.27912 & 1.00344 & 0.84298 & 0.73577 & 0.65682 & 0.59470 & 0.54454 \\
\hline \hline
\end{tabular}


Table 5: Results of the thermal conductivity measurements; thermal conductivity $\lambda$, liquid mole fraction $x_{\mathrm{TTIP}}$ and temperature $T$. The uncertainties are $u\left(x_{\mathrm{TTIP}}\right)=$ $0.0005 \mathrm{~mol} \mathrm{~mol}^{-1}, u(T)=0.2 \mathrm{~K}, u(\lambda)$ is given for each point in the table.

\begin{tabular}{c|cccc}
\hline \hline $\begin{array}{c}x_{\text {TTIP }} \\
\mathrm{mol} \mathrm{mol}^{-1}\end{array}$ & \multicolumn{4}{|c}{$\lambda / \mathrm{mW} \mathrm{m}^{-1} \mathrm{~K}^{-1}$} \\
\hline 0.0000 & 126.81 & \pm 3.15 & $122.22 \pm 5.11$ & $117.05 \pm 3.08$ \\
0.0401 & 126.85 & \pm 1.71 & $120.59 \pm 1.52$ & $115.68 \pm 1.43$ \\
0.0871 & 127.54 & \pm 1.47 & $122.46 \pm 1.72$ & $114.64 \pm 2.55$ \\
0.1382 & 127.43 & \pm 1.40 & $122.24 \pm 1.38$ & $116.21 \pm 1.24$ \\
0.1994 & 126.71 & \pm 1.42 & $123.38 \pm 1.30$ & $116.31 \pm 1.41$ \\
0.2718 & 127.89 & \pm 1.48 & $123.79 \pm 1.46$ & $116.48 \pm 1.78$ \\
0.3593 & 127.49 & \pm 1.39 & $124.26 \pm 1.41$ & $117.12 \pm 1.34$ \\
0.4654 & 131.27 & \pm 1.51 & $123.28 \pm 1.51$ & $116.79 \pm 1.52$ \\
0.5988 & 130.34 & \pm 1.45 & $122.55 \pm 1.34$ & $116.21 \pm 2.75$ \\
0.7700 & 132.18 & \pm 1.40 & $123.72 \pm 1.47$ & $116.76 \pm 1.58$ \\
1.0000 & 131.98 & \pm 1.53 & $125.39 \pm 1.43$ & $117.06 \pm 1.62$ \\
\hline \hline
\end{tabular}

Table 6: Results of the isobaric heat capacity measurements; isobaric heat capacity $c_{\mathrm{p}}$, liquid mole fraction $x_{\mathrm{TTIP}}$ and temperature $T$. The uncertainties are $u_{\mathrm{r}}\left(c_{\mathrm{p}}\right)=5 \%, u\left(x_{\mathrm{TTIP}}\right)=0.0005 \mathrm{~mol} \mathrm{~mol}^{-1}$ and $u(T)=0.2 \mathrm{~K}$.

\begin{tabular}{c|ccc}
\hline \hline $\begin{array}{c}x_{\mathrm{TTIP}} \\
\mathrm{mol} \mathrm{mol}^{-1}\end{array}$ & $T=293.15 \mathrm{~K}$ & $313.15 \mathrm{~K}$ & $333.15 \mathrm{~K}$ \\
\hline 0.0000 & 182.6 & 186.9 & 191.1 \\
0.0401 & 193.8 & 196.0 & 200.6 \\
0.0871 & 206.9 & 211.7 & 215.4 \\
0.1382 & 219.7 & 224.9 & 227.6 \\
0.1994 & 235.2 & 242.3 & 243.7 \\
0.2718 & 255.0 & 262.8 & 264.3 \\
0.3593 & 277.3 & 287.5 & 289.2 \\
0.4654 & 313.8 & 313.8 & 319.5 \\
0.5988 & 344.7 & 346.8 & 353.2 \\
0.7700 & 396.5 & 396.5 & 401.4 \\
1.0000 & 457.6 & 466.1 & 466.1 \\
\hline \hline
\end{tabular}


Table 7: Results of the self-diffusion coefficient measurements; self-diffusion coefficient $D_{i}$ of component $i$, liquid mole fraction $x_{\text {TTIP }}$ and temperature $T$. The uncertainties are $u\left(D_{i}\right)=5.5 \cdot 10^{-11} \mathrm{~m}^{2} \mathrm{~s}^{-1}, u\left(x_{\mathrm{TTIP}}\right)=0.0005 \mathrm{~mol} \mathrm{\textrm {mol } ^ { - 1 }}$ and $u(T)=0.2 \mathrm{~K}$.

\begin{tabular}{|c|c|c|c|c|c|c|}
\hline \multirow{3}{*}{$\begin{array}{c}x_{\text {TTIP }} \\
\mathrm{mol} \mathrm{mol}^{-1}\end{array}$} & \multicolumn{6}{|c|}{$\bar{D}_{i} / 10^{-9} \mathrm{~m}^{2} \mathrm{~s}^{-1}$} \\
\hline & \multicolumn{2}{|c|}{$T=288.15 \mathrm{~K}$} & \multicolumn{2}{|c|}{$298.15 \mathrm{~K}$} & \multicolumn{2}{|c|}{$308.15 \mathrm{~K}$} \\
\hline & $i=p$-xylene & TTIP & $p$-xylene & TTIP & $p$-xylene & TTIP \\
\hline 0.0108 & 2.0789 & 1.1880 & 2.3993 & 1.5613 & 2.7528 & 1.6825 \\
\hline 0.0708 & 1.9564 & 1.1179 & 2.2523 & 1.3160 & 2.5750 & 1.5246 \\
\hline 0.1578 & 1.8357 & 0.9852 & 2.0898 & 1.1279 & 2.4274 & 1.3365 \\
\hline 0.2876 & 1.6315 & 0.8189 & 1.8922 & 0.9634 & 2.2141 & 1.1626 \\
\hline 0.5607 & 1.3377 & 0.5945 & 1.6155 & 0.7594 & 1.9441 & 0.9509 \\
\hline 0.9851 & 0.8475 & 0.2936 & 1.1102 & 0.4659 & 1.5032 & 0.6470 \\
\hline
\end{tabular}

Table 8: Antoine parameters for the vapor pressures of pure TTIP and $p$-xylene obtained from a fit to the referenced experimental data from the literature, cf. Eq. (3).

\begin{tabular}{l|cccc}
\hline \hline & $A$ & $B$ & $C$ & Ref. \\
\hline TTIP & 12.9502 & 2998.2 & -139.586 & {$[24,25]$} \\
$p$-xylene & 14.0775 & 3344.9 & -57.910 & {$[26]$} \\
\hline \hline
\end{tabular}

Table 9: NRTL parameters for the system TTIP (1) + p-xylene (2) obtained from a fit to experimental data from the present work, cf. Eqs. (2) - (5).

\begin{tabular}{l|c|c}
\hline \hline Non-randomness parameter & $\alpha_{12}=\alpha_{21}$ & 0.49 \\
& $\tau_{12}$ & -1.1078 \\
NRTL fit parameters & $\tau_{21}$ & 0.8699 \\
\hline \hline
\end{tabular}


Table 10: Parameters of the correlations for the pure component properties of TTIP and $p$-xylene.

\begin{tabular}{|c|c|c|c|c|c|}
\hline Property & Eq. & Component & $\bar{a} a$ & $\overline{c b}$ & CC \\
\hline Molar volume $v / \mathrm{m}^{3} \mathrm{~mol}^{-1}$ & (8) & $\begin{array}{c}\text { TTIP } \\
p \text {-xylene }\end{array}$ & $\begin{array}{l}-1.1177 \cdot 10^{-6} \\
8.2479 \cdot 10^{-5}\end{array}$ & $\begin{array}{l}1.4478 \cdot 10^{-6} \\
1.3870 \cdot 10^{-7}\end{array}$ & $\begin{array}{c}-1.4989 \cdot 10^{-9} \\
0\end{array}$ \\
\hline Viscosity $\eta / \mathrm{mPa} s$ & (11) & $\begin{array}{c}\text { TTIP } \\
\text { p-xylene }\end{array}$ & $\begin{array}{l}1.0491 \cdot 10^{-8} \\
2.9350 \cdot 10^{-3}\end{array}$ & $\begin{array}{l}5.6646 \cdot 10^{3} \\
1.5259 \cdot 10^{3}\end{array}$ & $\begin{array}{l}5.3571 \cdot 10^{-1} \\
1.0526 \cdot 10^{-1}\end{array}$ \\
\hline Thermal conductivity $\lambda / \mathrm{mW} \mathrm{m} \mathrm{m}^{-1} \mathrm{~K}^{-1}$ & (8) & $\begin{array}{c}\text { TTIP } \\
p \text {-xylene }\end{array}$ & $\begin{array}{l}2.4174 \cdot 10^{2} \\
1.9823 \cdot 10^{2}\end{array}$ & $\begin{array}{l}-3.7335 \cdot 10^{-1} \\
-2.4331 \cdot 10^{-1}\end{array}$ & $\begin{array}{l}0 \\
0\end{array}$ \\
\hline Isobaric heat capacity $c_{\mathrm{p}} / \mathrm{J} \mathrm{mol}^{-1} \mathrm{~K}^{-1}$ & (8) & $\begin{array}{c}\text { TTIP } \\
p \text {-xylene }\end{array}$ & $\begin{array}{l}3.9646 \cdot 10^{2} \\
1.2443 \cdot 10^{2}\end{array}$ & $\begin{array}{l}2.1337 \cdot 10^{-1} \\
2.0026 \cdot 10^{-1}\end{array}$ & $\begin{array}{l}0 \\
0\end{array}$ \\
\hline
\end{tabular}

Table 11: Parameters of the Redlich-Kister correlation for molar volume, thermal conductivity and isobaric heat capacity (cf. Eq. (9)) and parameters of the JouybanAcree correlation for viscosity (cf. Eq. (10)).

\begin{tabular}{l|c|ccc}
\hline \hline & Eq. & $E$ & $F$ & $G$ \\
\hline Molar volume $v / \mathrm{m}^{3} \mathrm{~mol}^{-1}$ & $(9)$ & $1.7034 \cdot 10^{-5}$ & $-5.3617 \cdot 10^{-8}$ & - \\
Viscosity $\eta / \mathrm{mPa} s$ & $(10)$ & $-2.7876 \cdot 10^{1}$ & $-2.6167 \cdot 10^{1}$ & $-1.1670 \cdot 10^{2}$ \\
Thermal conductivity $\lambda / \mathrm{mW} \mathrm{m}^{-1} \mathrm{~K}^{-1}$ & $(9)$ & 0 & 0 & - \\
Isobaric heat capacity $c_{\mathrm{p}} / \mathrm{J} \mathrm{mol}^{-1} \mathrm{~K}^{-1}$ & $(9)$ & $-9.1239 \cdot 10^{0}$ & 0 & - \\
\hline \hline
\end{tabular}


Table 12: Parameters of the correlations for the self-diffusion coefficients, cf. Eq. (12).

\begin{tabular}{l|cccccc}
\hline \hline & $a$ & $b$ & $c$ & $d$ & $e$ & $f$ \\
\hline TTIP & $-5.4126 \cdot 10^{0}$ & $2.2988 \cdot 10^{-2}$ & $4.9976 \cdot 10^{0}$ & $-2.2444 \cdot 10^{-2}$ & $-4.3365 \cdot 10^{0}$ & $1.6975 \cdot 10^{-2}$ \\
$p$-xylene & $-8.5659 \cdot 10^{0}$ & $3.2589 \cdot 10^{-2}$ & $4.8451 \cdot 10^{0}$ & $-1.3521 \cdot 10^{-2}$ & $-3.5545 \cdot 10^{0}$ & $1.3354 \cdot 10^{-2}$ \\
\hline \hline
\end{tabular}

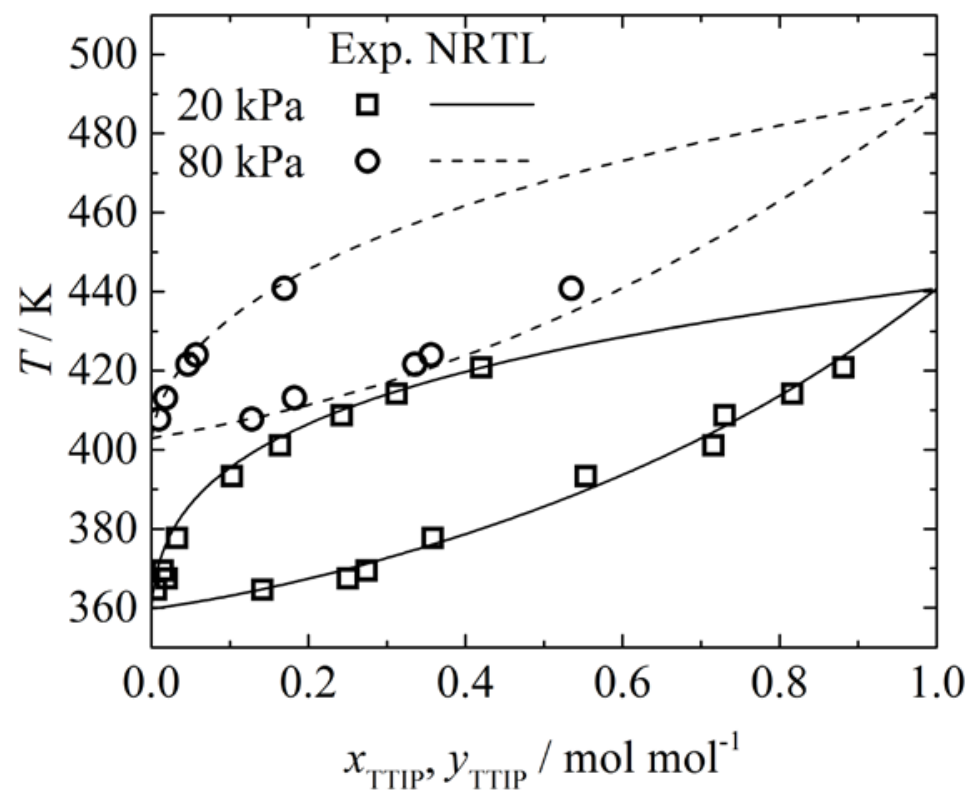

Figure 1: VLE of TTIP $+p$-xylene. Symbols are experimental results for the pressures (口) $20 \mathrm{kPa}$ and (○) $80 \mathrm{kPa}$. Lines show the NRTL model, cf. Eqs. (2) - (5), with parameters from Tables 8 and 9. 


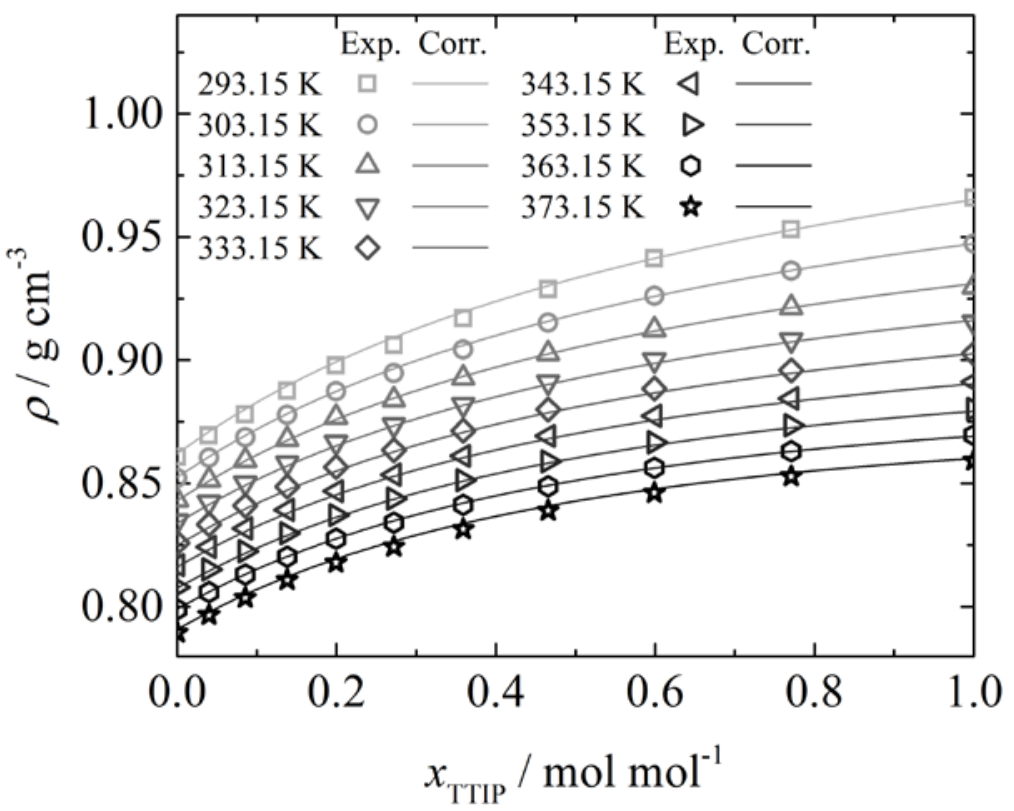

Figure 2: Densities $\rho$ of mixtures of TTIP and $p$-xylene at $101.3 \mathrm{kPa}$ and different temperatures. Symbols are experimental results. Experimental uncertainties are always within symbol size. Lines are empirical correlations, cf. Eqs. (7) - (9), with parameters from Tables 10 and 11. 


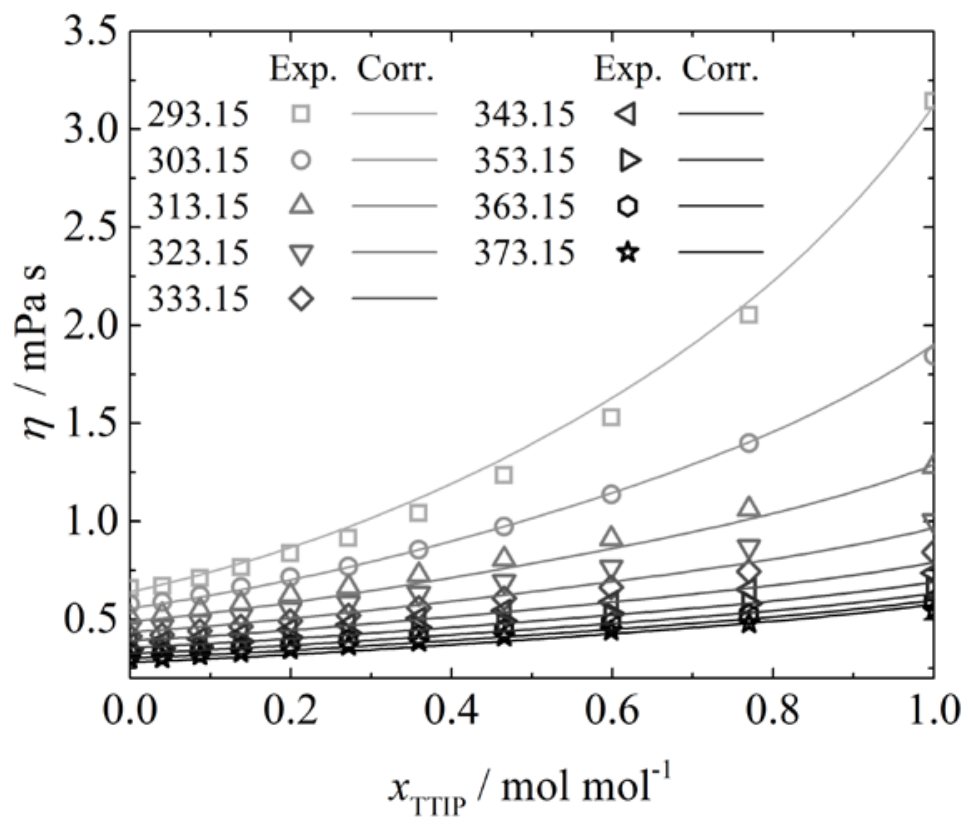

Figure 3: Viscosities $\eta$ of mixtures of TTIP and p-xylene at $101.3 \mathrm{kPa}$ and different temperatures. Symbols are experimental results. Experimental uncertainties are always within symbol size. Lines are empirical correlations, cf. Eqs. (10) - (11), with parameters from Tables 10 and 11. 


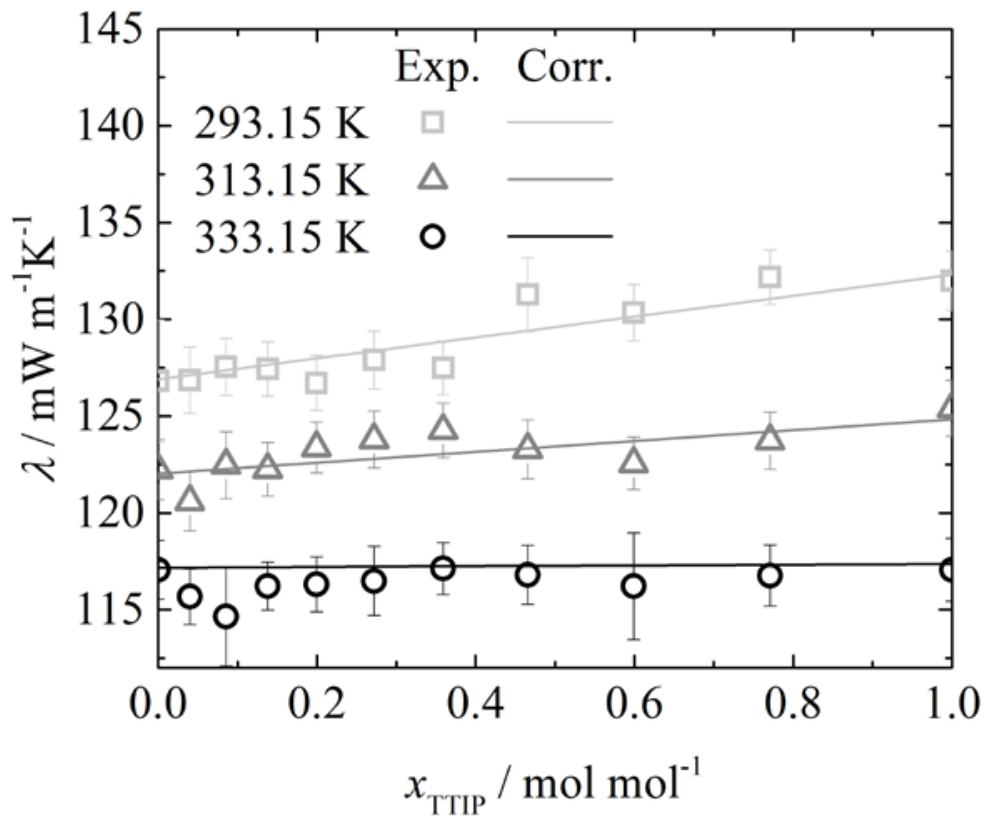

Figure 4: Thermal conductivities $\lambda$ of mixtures of TTIP and $p$-xylene at $101.3 \mathrm{kPa}$ and different temperatures. Symbols are experimental results. Error bars are standard deviations of 10 subsequent measurements. Lines are empirical correlations, cf. Eqs. (7) - (9), with parameters from Tables 10 and 11. 


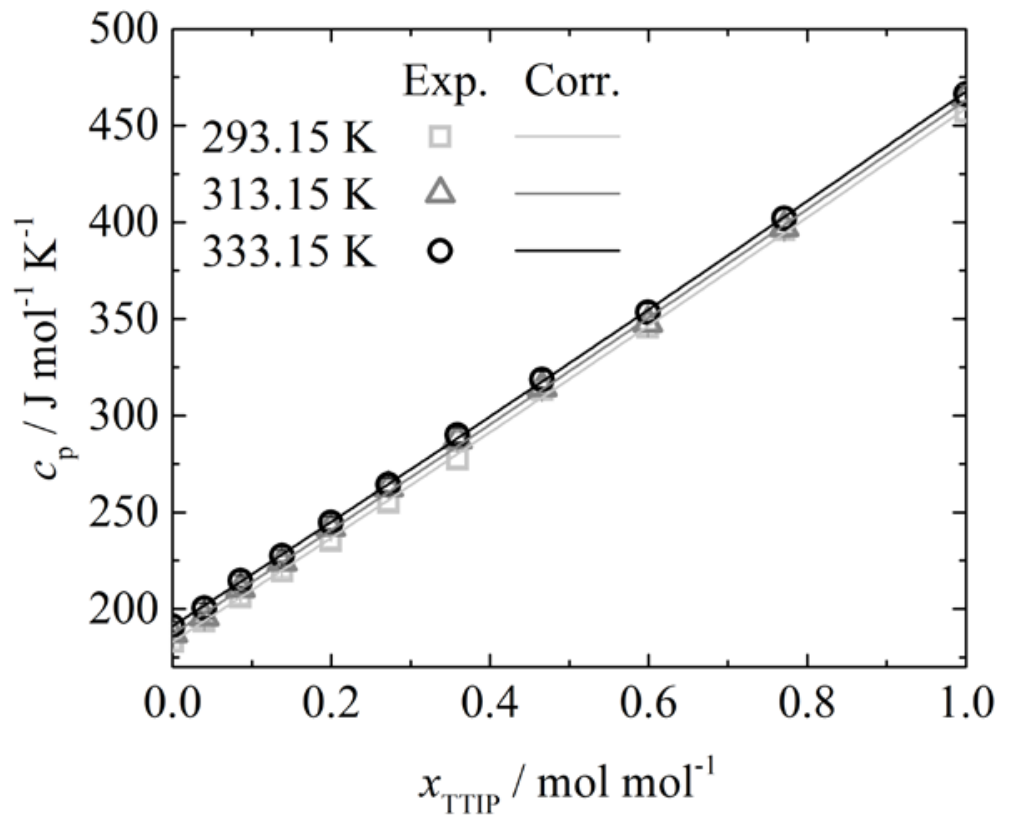

Figure 5: Isobaric heat capacity $c_{\mathrm{p}}$ of mixtures of TTIP and $p$-xylene at $101.3 \mathrm{kPa}$ and different temperatures. Symbols are experimental results. Experimental uncertainties are always within symbol size. Lines are empirical correlations, cf. Eqs. (7) - (9), with parameters from Tables 10 and 11. 


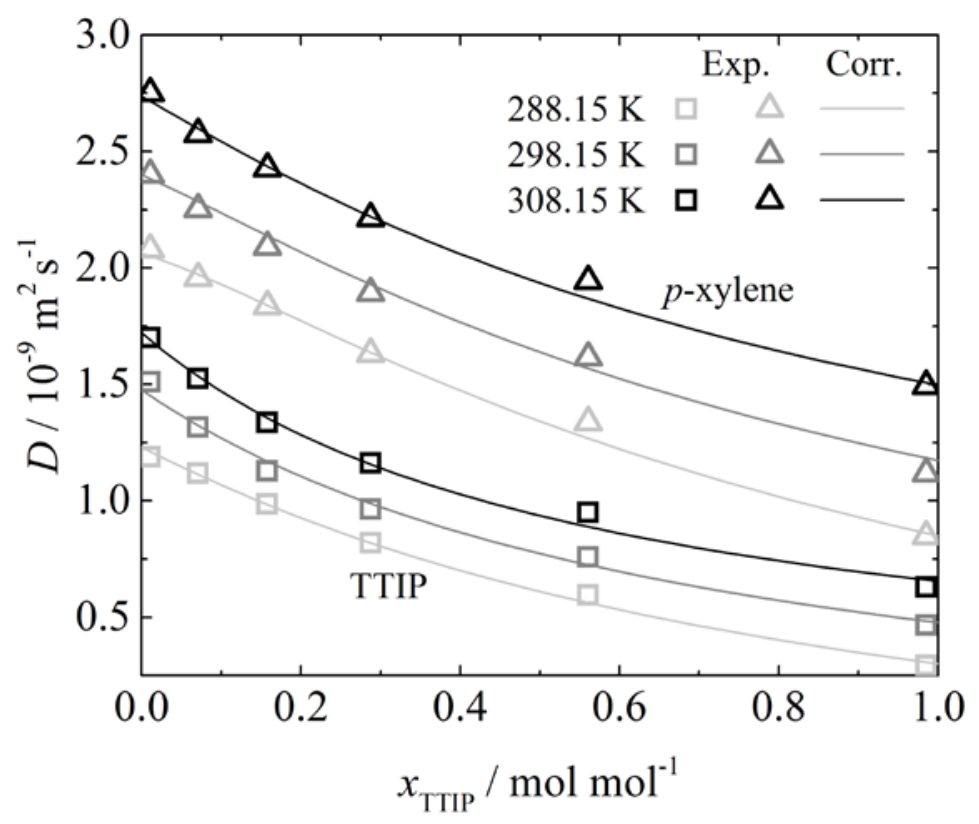

Figure 6: Self-diffusion coefficients $D$ of TTIP and $p$-xylene in mixtures of the substances at $101.3 \mathrm{kPa}$ and different temperatures. Symbols are experimental results for ( $\square$ ) TTIP and $(\Delta) p$-xylene. Experimental uncertainties are always within symbol size. Lines are empirical correlations, cf. Eq. (12), with parameters from Table 12. 